\title{
Algumas Receitas de Oscilações Químicas e de Estruturas Espaciais
}

$\mathrm{N}$ OMO COMPLEMENTO AO ARTIGO DE J.C. Micheau et al., este número do boletim dedica as secções de Actividades na sala de aula e de Actividades no laboratório a reacções oscilantes. Optou-se aqui por fornecer os pontos de partida, isto é, as receitas para algumas dessas reacções. 0 estudo cinético e mecanístico deste tipo de reacçōes tem bons pontos de apoio em literatura recente, de onde se destacam os trabaIhos de Pojman et al. [1-3] e um trabaIho recente de Cervellati et al. [4].

Existem diversas fontes para receitas de reacções oscilantes, sendo as mais citadas os livros gerais de Summerlin e Ealy [5] e de Shakhashiri [6], assim como diversos artigos no J. Chem. Ed. [7]; tendo-se recorrido ainda a um artigo de J.-C. Micheau [8]. As reacções oscilantes podem dar origem a variaçōes de cor no tempo - reacçōes "relógio" - ou a estruturas espaciais organizadas. Nas primeiras, os reagentes são adicionados e mantidos sob agitação, ocorrendo oscilações entre duas cores após um período de indução - é o caso das reacções 1. e 2. abaixo apresentadas e que são exemplos clássicos de reacções "relógio". Na ausência de agitação, colocando por exemplo a mistura como uma camada fina numa placa de Petri, a difusão acopla com a reacção oscilante levando à propagação da reacção pelo meio, o que se traduz pela formação de anéis ou espirais de cor diferente da do fundo. A reacção de Belousov-Zhabotinsky catalizada pela ferroína e apresentada na folha de Actividades na sala de aula é um exemplo deste tipo de reacções oscilantes.

A receita 3. abaixo apresentada dá origem a estruturas espaciais de natureza diferente. Quando uma camada horizontal de um líquido (por exemplo entre duas placas de vidro) é submetida a um fluxo de calor pela parte inferior, é possivel observar a formação de células de convecção térmica acima de um determinado gradiente de temperatura ao longo da camada de líquido. São as designadas células de Bénard, que foi quem observou o fenómeno pela primeira vez em 1900. O afastamento do equilibrio aumenta com a diferença de temperatura entre as placas e o sistema usa parte da energia para se auto-organizar. Na receita apresentada, usa-se uma reacção fotoquímica para melhor visualizar essas células de convecção térmica.

\section{Oscilações químicas I - Relógio de iodo}

\subsection{Objectivo}

Pretende-se realizar a reacção de Briggs e Rauscher, conhecida pelo nome de relógio de iodo ou de oscilador de iodato/iodo/peróxido. Podem observarse oscilações temporais amarelo-azul escuro.

\subsection{Material necessário}

Um erlenmeyer de $100 \mathrm{ml}$; uma barra de agitação; uma placa de agitação magnética com aquecimento; 2 copos de $100 \mathrm{ml}$; um copo de $250 \mathrm{ml}$.

\subsection{Produtos necessários}

lodato de potássio $\left(\mathrm{KIO}_{3}\right)$; ácido sulfúrico $2 \mathrm{M}$; ácido malónico $\left(\mathrm{CH}_{2}\left(\mathrm{CO}_{2} \mathrm{H}\right)_{2}\right)$; sulfato de manganês(II) $\left(\mathrm{MnSO}_{4}\right)$; amido; peróxido de hidrogénio a 30\% (v/v); água destilada.

\subsection{Preparação das três soluções iniciais}

Solução A. Preparar uma soluçăo de iodato de potássio do seguinte modo: adicionar 4,28 $\mathrm{g}$ de $\mathrm{KIO}_{3}$ e $8 \mathrm{ml}$ de ácido sulfúrico $2 \mathrm{M}$ a uma pequena quantidade de água destilada; acertar o volume a $100 \mathrm{ml}$ com água destilada.

SOLuÇÃo B. Preparar uma solução de ácido malónico e $\mathrm{Mn}$ (II) do seguinte modo: adicionar $1,56 \mathrm{~g}$ de ácido malónico e $0,45 \mathrm{~g}$ de $\mathrm{MnSO}_{4}$ a uma pequena quantidade de água destilada; acertar o volume a $100 \mathrm{ml}$ com água destilada.

Solução c. Preparar uma solução de amido a $1 \%$ do seguinte modo: fazer uma pasta de $1 \mathrm{~g}$ de amido com um pouco de água destilada quente e adicioná-la a água destilada em ebulição para um volume final de $\sim 100 \mathrm{ml}$.

\subsection{Realização da experiência}

Misturar $20 \mathrm{ml}$ de cada uma das soluções A, B e C no erlenmeyer de $100 \mathrm{ml}$ e iniciar a reacção por adição de 20 ml de peróxido de hidrogénio a 30\% (v/v), sob agitação magnética. Após 1 a 2 min, a solução inicialmente azul (devido à formação de iodo que forma um complexo azul com o amido), muda a cor para amarelo pálido (à medida que o iodo desaparece) e de novo, abruptamente, passa a azul, iniciando um novo ciclo. As oscilações acabam ao fim de 15 a 20 min, uma vez que alguns reagentes são consumidos em cada ciclo sem serem repostos.

Ao fim de alguns minutos, a mistura liberta $\mathrm{CO}_{2}$ devido à oxidação do ácido malónico. 

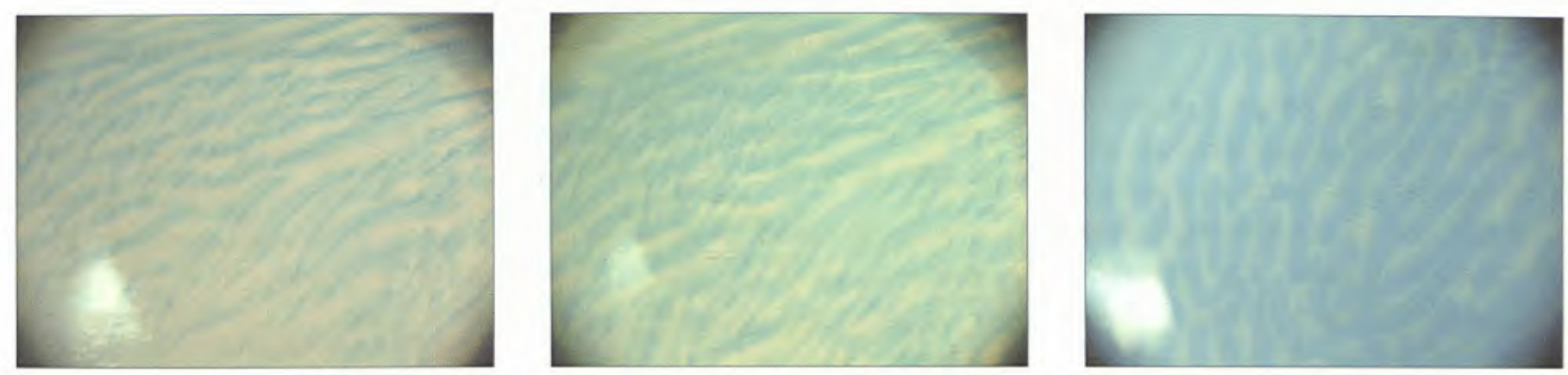

figura 1 Formação de estrias de convecção.

Se a mistura não for agitada, é também possivel observar mudanças de cor mas agora sob a forma de manchas amarelas e azuis através da solução.

\subsection{A evitar..}

É importante que a solução de ácido malónico não esteja preparada há muito tempo pois ela decompõe-se ao fim de algumas semanas.

\section{Oscilações químicas II Reacção de Belousov-Zhabotinsky catalisada por $\mathrm{Ce}^{4+} / \mathrm{Ce}^{3+}$}

\subsection{Objectivo}

Pretende-se realizar a reacção de Belousov-Zhabotinsky catalisada por $\mathrm{Ce}^{4+} / \mathrm{Ce}^{3+}$. Podem observar-se oscilações temporais incolor-amarelo. Esta foi a mudança de cor inicialmente observada por Belousov ao estudar o Ciclo de Krebs.

\subsection{Material necessário}

Um erlenmeyer de $200 \mathrm{ml}$; uma barra de agitação; uma placa de agitação magnética com aquecimento; um copo de $50 \mathrm{ml}$; dois copos de $25 \mathrm{ml}$.

\subsection{Produtos necessários}

Bromato de potássio $\left(\mathrm{KBrO}_{3}\right)$; ácido sulfúrico $6 \mathrm{M}$; ácido malónico $\left(\mathrm{CH}_{2}\left(\mathrm{CO}_{2}\right.\right.$ $\left.\mathrm{H})_{2}\right)$; sulfato de cério(IV) $\left(\mathrm{Ce}\left(\mathrm{SO}_{4}\right)_{2}\right)$; água destilada.

\subsection{Preparação das três soluções iniciais}

SOLuÇÃ̃o A. Preparar $40 \mathrm{ml}$ de uma solução aquosa 0,5 M de ácido malónico (52,1 g de ácido malónico por litro).
SOLuçÃo B. Preparar $20 \mathrm{ml}$ de uma solução de sulfato de cério(IV) $0,01 \mathrm{M}$ em ácido sulfúrico $6 \mathrm{M}$.

SOLuÇĀo C. Preparar $20 \mathrm{ml}$ de uma solução aquosa de bromato de potássio $0,25 \mathrm{M}\left(41,8 \mathrm{~g}\right.$ de $\mathrm{KBrO}_{3}$ por litro). (0 uso de $\mathrm{NaBrO}_{3}$ torna mais fácil esta preparação, dada a sua maior solubilidade em água),

\subsection{Realização da experiência}

Misturar as soluções A e B num erlenmayer ou copo de precipitação de 250 ml e adicionar a solução c, sob agitação. Após cerca de 3 min, a solução começa a oscilar, alternando entre incolor e e amarelo. As oscilações perduram, no mínimo, 10 a $15 \mathrm{~min}$.

\subsection{A evitar...}

É importante que a solução de ácido malónico não esteja preparada há muito tempo pois ela decompõe-se ao longo do tempo.

\section{Estruturas espaciais convectivas}

\subsection{Objectivo}

Pretende-se visualizar a convecção térmica natural em camada fina (do tipo Rayleigh-Bénard) com a ajuda de uma reacção fotoquímica. Observa-se a formação de estrias brancas num fundo azul.

\subsection{Material necessário}

Uma caixa de Pétri em pyrex com fundo bastante plano e 100 a 150 mm de diâmetro; uma microespátula; 3 frascos de $100 \mathrm{ml}$; uma proveta de $25 \mathrm{ml}$; uma lanterna (com lâmpada de halogénio de $150 \mathrm{~W}$ ) que possa ser posta vertical- mente (experimentar também com um retroprojector, iluminando a placa de Pétri por baixo).

\subsection{Produtos necessários}

Azul de metileno; solução aquosa tamponizada a $\mathrm{pH}=9$; sal dissódico dihidratado do ácido etilenodiaminotetraacético (EDTA); água destilada.

\subsection{Preparação das suas soluções iniciais}

SOLUÇĀO A. No primeiro frasco de 100 $\mathrm{ml}$, adicionar $25 \mathrm{~g}$ do sal de EDTA a 90 $\mathrm{ml}$ da solução tamponizada a $\mathrm{pH}=9$. SOLuÇÃo B. No segundo frasco, colocar $75 \mathrm{ml}$ de água destilada e alguns $\mathrm{mg}$ (uma ponta de microespátula) de azul de metileno; obtém-se uma solução azul escura.

As soluções assim preparadas conservam-se durante várias semanas.

\subsection{Realização da experiência}

Colocar a caixa de Pétri sobre uma folha de papel branco numa superfície bem horizontal. Num frasco de $100 \mathrm{ml}$, misturar $10 \mathrm{ml}$ da solução A com $10 \mathrm{ml}$ da solução B. Deitar lentamente essa mistura na caixa de Pétri até que o fundo esteja completamente coberto. Com a lanterna, iluminar então a superfície da placa. Começam a aparecer pequenas estrias brancas sobre o fundo azul. A estruturação espacial perdura durante a irradiação. O contraste esvai-se quando se pára a irradiação, mas é ainda possível observar o processo inverso (estrias azuis sob fundo branco) durante o arrefecimento, figura 1. A solução torna a ser completamente azul e pode ser reutilizada diversas vezes. 